
\title{
Research S Suare \\ Identification of Antigenic Domains and Peptides from VP15 of White Spot Syndrome Virus and their Antiviral Effects in Marsupenaeus Japonicus
}

Jirayu Boonyakida

Shizuoka University

Jian Xu

East China Normal University

Jun Satoh

Fisheries Research Agency

Takafumi Nakanishi

Shizuoka University

Toru Mekata

Fisheries Research Agency

\section{Tatsuya Kato}

Shizuoka University

Enoch Y. Park ( $\nabla$ park.enoch@shizuoka.ac.jp )

Shizuoka University

\section{Research Article}

Keywords: White spot syndrome virus, VP15, Kuruma shrimp, Anti-WSSV peptide, gC1qR

Posted Date: January 13th, 2021

DOI: https://doi.org/10.21203/rs.3.rs-143155/v1

License: (c) (i) This work is licensed under a Creative Commons Attribution 4.0 International License. Read Full License 


\section{Abstract}

White spot syndrome virus (WSSV) is one of the most devastating pathogens in penaeid shrimp and can cause massive damage in shrimp aquaculture industries. Previously, the WSSV structural protein VP15 was identified as an antigenic reagent against WSSV infections. In this study, we truncated this protein into VP15 $5_{(1-25)}, \operatorname{VP15} 5_{(26-57)}, \operatorname{VP15}(58-80)$, and VP15 ${ }_{(1-25,58-80)}$. The purified proteins from the $E$. coli expression system were assayed as potential protective agents in Kuruma shrimp (Marsupenaeus japonicus) using the prime-and-boost strategy. Among the four truncated constructs, VP15 ${ }_{(26-57)}$ provided a significant improvement in the shrimp survival rate after 20 days of viral infection. Subsequently, four peptides (KR11, SR11, SK10, and KK13) from VP15 $5_{(26-57)}$ were synthesized and applied in an in vivo assay. Our results showed that SR11 could significantly enhance the shrimp survival rate, as determined from the accumulated survival rate. Moreover, a multiligand binding protein with a role in the host immune response and a possible VP15-binding partner, MjgC1qR, from the host $M$. japonicus were employed to test its binding with the VP15 protein. GST pull-down assays revealed that MjgC1qR binds with VP15, VP15 $(26-57)$, and SR11. Taken together, we conclude that SR11 is a determinant antigenic peptide of VP15 conferring antiviral activity against WSSV.

\section{Introduction}

White spot disease (WSD), caused by white spot syndrome virus (WSSV), has been known as one of the most devastating diseases of farmed shrimp worldwide since its first occurrence in Taiwan in 1992 ${ }^{1-3}$. Since then, substantial global losses due to WSD alone have been approximately US\$15 billion annually, with an increasing rate of US\$1 billion/year. ${ }^{4,5}$ WSSV infection in a shrimp pond could result in a high mortality rate within a single week, especially in penaeid shrimp (e.g., Marsupenaeus japonicus, Litopenaeus vannamei, Penaeus monodon, and Fenneropenaeus indicus) ${ }^{6,7}$. Clinical signs in WSDsuffering shrimp include lethargy, anorexia, reduction in food uptake, reduced preening activities, loose cuticle, reddish discoloration, and white calcified spots of $0.5-3 \mathrm{~mm}$ in diameter on the exoskeleton ${ }^{8,9}$.

WSSV is the sole member of the genus Whispovirus and the only genus in the Nimaviridae family $10-12$. The virus is a large, enveloped virus containing supercoiled circular double-stranded DNA (dsDNA) with an unknown functional tail-like appendage $\mathrm{e}^{12,13}$. The virion has a size of approximately $80-100 \times 250-$ $350 \mathrm{~nm}$ with a rod-shaped nucleocapsid covered by a trilaminar membrane ${ }^{14}$. The genomic DNA is 285$305 \mathrm{kbp}$ long with nine tandem repeat conserved regions and 180 putative open reading frames (ORFs). However, most of the ORF-encoded proteins have no homology to the known proteins in databases ${ }^{15-18}$. Proteomic analysis of WSSV revealed that the virus contains at least six major virion proteins (VPs). VP19, VP24, VP26, and VP28 were identified as envelope proteins, while VP15 and VP664 were identified as nucleocapsid-associated proteins ${ }^{19,20}$. There is evidence that envelope proteins can form a protein complex that plays a crucial role in host-virus interactions ${ }^{21-23}$. 
However, there is no practical method to prevent WSSV infection in shrimp and to manage the spread of this disease. Hence, it is necessary to develop a treatment against the virus. To date, following the concept of "trained immunity", several kinds of WSSV immunizing agents have been tested, including viral protein subunits, attenuated WSSV, and DNA-/RNA-based agents ${ }^{24,25}$. Most recombinant subunit vaccines investigated have been based on VP19, VP24, VP26, VP28, VP292, and VP466, and among them, VP28 has been widely studied ${ }^{26-30}$. These viral subunits were confirmed to improve the survival rate after challenging shrimp with WSSV. Recently, we reported that VP15 can also provide a protective effect in Kuruma shrimp (M. japonicus) against WSSV after immune prime-and-boost via intramuscular injection ${ }^{31}$.

WSSV-VP15 is an 80 amino acid protein with an extremely high basic pl value of 12.49 , only showing homology with the DNA-binding proteins of eukaryotic origin and a baculovirus p6.9 protein ${ }^{32}$. Some studies have suggested that VP15 may be involved in viral genome packaging into the capsid and a major nucleocapsid protein with the ability to self-interact, forming homomultimers ${ }^{33,34}$. Although VP15 is a major nucleocapsid protein, its properties and functions have not been defined. No protein crystal structure has been reported yet, and only one trial used VP15-based material (DNA vaccine encoding VP15 ${ }^{35}$ ) for immunizing shrimp against WSSV. We have previously demonstrated that VP15 can enhance shrimp survivability after challenge with $\mathrm{WSSV}^{31}$. In this study, we attempted to determine the antigenic domain of the VP15 protein by in vivo animal experiments with $M$. japonicus using a purified truncated VP15 series and synthetic peptides derived from VP15 at the peptide level. To further explore the mechanism of antigenicity involved, we also investigated the possible interaction between VP15 and its host protein partner, a gC1qR homolog from M. japonicus (MjgC1qR), via GST pull-down assay.

\section{Results}

\section{Expression and purification of truncated WSSV-VP15s.}

pGEX-6P-1, which has a glutathione S-transferase (GST, molecular weight; $26 \mathrm{kDa}$ ) fusion system, was genetically fused with the VP15 gene as the GST-VP15 fusion gene, and the constructed plasmid was used as a template to generate a truncated series of VP15 (Fig. 1A and B). The protein expression was driven by IPTG induction under the control of the tac promoter. The sizes of the GST-fused truncated VP15 series members were predicted to be $30.8,31.6,30.5$, and $33.4 \mathrm{kDa}$ for VP15 $5_{(1-25)}, \mathrm{VP} 15_{(26-57)}$, VP15 $(58-80)$, and VP15 $(1-25,58-80)$, respectively, while that of GST-VP15 was $37.0 \mathrm{kDa}$. The expression of recombinant proteins was confirmed by both SDS-PAGE (Fig. 1C) and western blotting with an antiDYKDDDDK antibody (Fig. 1D). The proteins were then purified from E. coli soluble fractions using GST affinity chromatography (Fig. 1E), and the yield of purified proteins obtained from $1 \mathrm{~L}$ culture was $3.3 \mathrm{mg}$ for GST, $5.3 \mathrm{mg}$ for VP15, $5.7 \mathrm{mg}$ for VP15 $(1-25), 6.3 \mathrm{mg}$ for VP15 $(26-57), 8.4 \mathrm{mg}$ for VP15 $(58-80)$, and $4.0 \mathrm{mg}$ for $\operatorname{VP} 15_{(1-25,58-80)}$. 


\section{Vaccination and challenge experiment using truncated VP15s.}

The partially purified GST-fused full-length VP15 and truncated VP15 series were subsequently intramuscularly (IM)-injected into Kuruma shrimp to assess their anti-WSSV activity. Five groups were immunized twice at days 0 and 20 using purified protein at a dose of $10 \mu \mathrm{g} / \mathrm{g}$ shrimp and then challenged at day 10 after the second injection (Fig. 2A). Two groups (PBS and GST) were mock-treated as two independent negative controls. All groups were challenged with WSSV at a dose of $2.69 \times 10^{4}$ DNA copies/shrimp.

The PBS and GST control groups showed a drastic decrease in survival rate from day 4 to day 7 and reached relative percent survival (RPS) values of $20 \%$ and $33.3 \%$ at 20 days post infection (dpi). A group of shrimp receiving VP15 $5_{(1-25)}$ showed an RPS of $31.6 \%$, a similar trend to that of the GST group, indicating that VP15 ${ }_{(1-25)}$ failed to provide a protective effect against WSSV. Groups of shrimp injected with VP15, VP15 $(58-80)$, or VP15 1 -25,58-80) showed an RPS at 20 dpi of $42.1 \%, 47.6 \%$, and $38.9 \%$, respectively. However, VP15 ${ }_{(26-57)}$ provided a protective effect against WSSV with a final RPS of $57.9 \%$ at $20 \mathrm{dpi}$ (Fig. 2B), which was the highest value among the experimental groups and was the only group showing a significant difference in survival rates compared with the controls.

\section{Vaccination and challenge experiment using VP15-derived peptides.}

To investigate the antigenic effects of VP15 at the peptide level, VP-15-derived peptides were designed based on the amino acid sequence of VP15 $(26-57)$ and chemically synthesized (purity $>95 \%$ ). As demonstrated in Fig. 3A, the peptides were KR11 (KTKSRRGSKKR), SR11 (STTAGRISKRR), KK13 (KRRSPSMKKRAGK), and SK10 (SPSMKKRAGK). Each peptide was IM-injected into the shrimp to screen for its protective effects against WSSV. Six groups of shrimp (15 individuals each) were set up with one PBS control group and five experimental groups. The protective effects of the four peptides were compared with those from GST-VP15 $26-57$. The shrimp were immunized twice, as shown in Fig. 3B, with a dose of $10 \mu \mathrm{g} / \mathrm{g}$ shrimp of peptide or the recombinant protein and observed for 14 days after the WSSV challenge. Our screening experiment revealed that SR11 could provide a prominent protective effect with a final RPS of $\sim 80 \%$, similar to GST-VP15 $26-57$ at 14 dpi. The KR11-, SK10-, and KK13-injected groups showed an RPS of $54 \%$ at the end of observation, similar to the PBS group (RPS of 53\%) (Fig. 3C). From this result, we interpreted that the KR11, SK10, and KK13 did not provide protective effects, as the RPS value was the same as that of the PBS control, while SR11 enhanced the resistance against WSSV. Therefore, SR11 was considered to be an antigenic peptide against WSSV in M. japonicus.

To verify the effect of the SR11 peptide, a larger sample size of 25 individuals was tested along with the positive control, GST-VP15 (26-57), and the PBS negative control group. The two experimental groups were 
treated similarly (Fig. 3B) with the same dose of SR11 or GST-VP15 ${ }_{(26-57)}$. As shown in Fig. 3D, shrimp rapidly died from day 6 to day 10 in the PBS group, with a final RPS of $\sim 50 \%$. However, shrimp in the group receiving either GST-VP15 ${ }_{(26-57)}$ or SR11 showed RPSs of $77 \%$ and $73 \%$, respectively, at $20 \mathrm{dpi}$, indicating that SR11 could generate reproducible anti-WSSV effects.

\section{Sequence analysis, alignment, and phylogenetic analysis of MjgC1qR.}

The gC1qR of invertebrates has been suggested to be involved in innate immunity against pathogens by acting as a pathogen recognition receptor ${ }^{36,37}$. There is evidence showing that $\mathrm{gC} 1 \mathrm{qR}$ might interact with VP15, hence interrupting WSSV replication ${ }^{3}$. We also hypothesized that gC1qR from M. japonicus (MjgC1qR) might interact with VP15 as well. gC1qRs have been identified from many invertebrate species but not from Kuruma shrimp. We then attempted to generate and analyze the cDNA sequence of MjgC1qR. To this end, bioinformatic analysis was performed to compare MjgC1qR with the reported $\mathrm{gC1qR(s)}$ from the database. The obtained full-length cDNA of MjgC1qR was $1120 \mathrm{bp}$, consisting of $98 \mathrm{bp}$ of a $5^{\prime}$-untranslated region (UTR), $786 \mathrm{bp}$ of an open reading frame (ORF), and $336 \mathrm{bp}$ of a 3'-UTR (including the stop codon) with one mRNA instability element (ATTTA). The ORF encodes a 261 amino acid-long protein with an MW of $29.2 \mathrm{kDa}$ and a theoretical $p /$ of 4.74 . The protein also contains an $\mathrm{N}$ terminal mitochondrial targeting sequence with a length of 44 amino acids, a mitochondrial acidic matrix (MAM33) domain (residues 34-213) at its C-terminus, and one arginine-glycine-aspartic acid (RGD) motif (Supplementary information Fig. S3). Comparative multiple alignment of gC1qR amino acid sequences from various species revealed a highly conserved MAM33 domain and cell attachment RGD motif across the invertebrate species. MjgC1qR also shared high identity with other invertebrate gC1qRs $(93.5 \%$ identity with Penaeus vannamei, 92\% with Penaeus monodon, $90.5 \%$ with Penaeus chinensis, $74.3 \%$ with Eriocheir sinensis, $71.6 \%$ with Portunus trituberculatus, $71 \%$ with Macrobrachium rosenbergii, $70.2 \%$ with Palaemon carinicauda, 69.8\% with Macrobrachium nipponense, and $68.7 \%$ with Pacifastacus leniusculus) (Supplementary information Fig. S4). The phylogenetic tree revealed that MjgC1qR had a close evolutionary relationship to crustacean gC1qRs, especially gC1qR of $P$. vannamei (Supplementary information Fig. S5).

\section{Expression of MjgC1qR using the silkworm-bacmid expression vector system.}

The bacmid harboring the full-length MjgC1qR-His gene was directly injected for transfection of silkworm larvae. Hemolymph and fat body were collected at $5 \mathrm{dpi}$. Fat bodies were homogenized and analyzed for the expressed protein via western blot analysis. As shown in Fig. 4, MjgC1qR was expressed as a single protein product in silkworm larvae under the control of the polyhedrin promoter. The protein was detected in the silkworm fat body in both a soluble and an aggregated form by the anti-His antibody. The size of 


\section{VP15 and the SR11 peptide interact with MjgC1qR.}

The interactions of MjgC1qR with the candidate bait proteins were observed through GST pull-down assay. In this study, the candidate baits were GST-VP15, GST-VP15 (26-57), and the GST-fused peptide GSTSR11, as these proteins and peptides could provide protective effects in shrimp against WSSV. Before this experiment, GST-SR11 was expressed in E. coli (Supplementary information Fig. S6). As shown in Fig. 5A, the recombinant $\mathrm{MjgC1}$ qR protein interacted with all the candidate proteins as hypothesized but not with the control GST protein.

\section{Discussion}

VP15 of WSSV has been identified as one of the major WSSV structural proteins in the nucleocapsid fraction and has an affinity for nucleic acids, especially supercoiled DNA ${ }^{34}$. Our aim was to identify an antigenic determinant of VP15 that could enhance the shrimp survival rate upon WSSV infection. We designed truncated constructs by dividing VP15 into three regions: the N-region (first 25 amino acids), middle region (32 amino acids), and C-region (last 23 amino acids), and purified truncations from E. coli were then tested as "vaccines" in shrimp. Purification of GST-VP15 suggested that the full-length protein might not be a stable protein, as it tended to be fragmented, as confirmed by SDS-PAGE analysis (Fig. 1E). The full-length VP15 protein (80 aa) has a theoretical size of approximately $35 \mathrm{kDa}$ and is rich in serine $(20 \%)$, arginine $(20 \%)$, and lysine $(21.2 \%)$. After purification, we observed protein bands below $35 \mathrm{kDa}$ and a thick protein band at $>30 \mathrm{kDa}$, which could not be observed by western blotting using antiFlag. Moreover, the truncated VP15s could be purified with a single main band corresponding to the predicted MW, except for VP15 $(1-25,58-80)$, which resulted in several productive bands below the main product.

To our knowledge, VP15 has barely been used as a protective agent against WSSV in penaeid shrimp, as this protein is usually not considered a part of the "infectome," a protein complex that comprises 14 different proteins, including VP19, VP24, VP26, and VP28, located on the viral surface ${ }^{21}$. VP15 was applied as a DNA vaccine in Peneus monodon, but it could not elicit any protection against WSSV ${ }^{35}$. In our previous study, we found that VP15, when administered to Kuruma shrimp IM at a dose of $0.04 \mathrm{mg} / \mathrm{g}$ shrimp using the prime-and-boost method, increased the RPS to $78 \%$ at $20 \mathrm{dpi}$. Moreover, the same GSTVP15 revealed a different result, in which the final RPS was approximately $43 \%$ with a dose of $0.01 \mathrm{mg} / \mathrm{g}$ shrimp using the same protocol ${ }^{31}$. This difference can be explained by the amount of the recombinant protein delivered to the shrimp. The dose was four times lower than the previous one. Therefore, we assumed that the protective effect of VP15 was dose dependent. 
Hence, in this study, the antigenic site of VP15 was determined via in vivo vaccination studies in Kuruma shrimp using an $E$. coli-derived VP15-truncated series including VP15 ${ }_{(1-25)}, \mathrm{VP} 15_{(26-57)}, \mathrm{VP} 15_{(58-80)}$, and VP15 $(1-25,58-80)$. Remarkably, only the group receiving VP15 ${ }_{(26-57)}$ showed a promising RPS higher than that obtained with VP15 and was significantly different from the controls. Based on the results, we hypothesized that VP15 $(26-57)$ might contain a specific region responsible for the anti-WSSV activity. To identify whether there is an antigenic determinant on VP15 ${ }_{(26-57)}$, the amino acid sequence of VP15 ${ }_{(26-57)}$ (KTKSRRGSKKRSTTAGRISKRRSPSMKKRAGK) was taken into account. Among the designed KR11, SR11, KK13, and SK10 peptides, only the SR11 $(n=11)$ group showed an improved survival rate at the end of observation, and this was reconfirmed in a larger sample size group $(n=25)$. The results were in good agreement with those of the previous experiment (Fig. $3 \mathrm{C}$ and D). Both experiments were performed in comparison to the parental protein $\operatorname{VP15}{ }_{(26-57)}$. Both shrimp receiving VP15 ${ }_{(26-57)}$ and those receiving SR11 showed a very similar trend during the observation periods, indicating that SR11 could be an antiviral determinant of VP15 $5_{(26-57)}$ responsible for triggering protective effects in vivo. It is still elusive whether or not the peptide with the longest span, KK13, could improve the shrimp survival rate, and the final RPS was close to the levels from KR11 and SK10. As KK13 has the amino acid sequence "SPSMKKRAGK" from SK10 and "KRR" from SR11, in in vivo experiments, "STTAGRIS(KRR)" of SR11 was revealed to be a critical region responsible for enhancing shrimp survival against the virus. One of the reasons we suggested this is that each of the synthesized peptides has a unique conformation and surface arrangement, and KK13 might lose its antigenicity with redundant sequences.

$\mathrm{gC} 1 \mathrm{qR}$ is considered a receptor for the globular head of $\mathrm{C} 1 \mathrm{q}$ of the classical complement pathway ${ }^{38,39}$. $\mathrm{gC} 1 \mathrm{qR}$ has been found on a cell surface acting as a receptor for a broad range of proteins and as a pathogen recognition receptor of innate immunity in many invertebrate species, suggesting that the protein may play a crucial role in an innate immune response against pathogenic bacteria and viruses $^{37,40,41}$. We hypothesized that MjgC1qR might interact with VP15 as well. Therefore, a novel MjgC1qR was identified from M. japonicus and expressed with the His-tag in the silkworm-bacmid expression system. Mammalian gC1qRs and reported crustacean gC1qRs contain mitochondrial targeting sequences at the $\mathrm{N}$-terminus and MAM33 domains at the $\mathrm{C}$-terminus, which direct the protein to the mitochondrial matrix for cleavage and maturation ${ }^{36,41-44}$. We also confirmed in the current study that MjgC1qR also has similar domains, indicating that MjgC1qR belongs to the gC1qR family and might function in the same way. Here, silkworm expression of recombinant MjgC1qR yielded a similar result (Fig. 4) to a previous report in which recombinant mammalian gC1qR expressed in Sf9 cells was processed due to the mitochondrial targeting sequence ${ }^{44}$. As investigated in GST pull-down assays, VP15, VP15 $(26-57)$, and SR11 interacted with MjgC1qR (Fig. 5A).

As illustrated in Fig. 5B, the current study provides a possible clue that the antiviral immune response could be triggered through an interaction between MjgC1qR and GST-VP15, GST-VP15 $(26-57)$, and GSTSR11. Based on the in vivo experiment and in vitro GST pull-down assay, it can be concluded that SR11 might be a linear antiviral determinant or an epitope of VP15. It can be explained that only a group of shrimp receiving SR11 showed an improvement in the survival rate. It is conceivable that shrimp might 
recognize "STTAGRISKRR" of VP15 as a nonself component through the pattern recognition receptors of their innate immune system, such as $\mathrm{gC} 1 \mathrm{qR}$, hence enhancing their response against the injected antigen. Recently, "trained immunity" has been evidenced in invertebrate innate immune systems, such as those of shrimp ${ }^{24,45}$. Several studies have demonstrated that shrimp immune priming with inactivated pathogenic bacteria (e.g., Vibrio harveyi, V. alginolyticus, and $V$. anguillarum) could protect them from vibriosis ${ }^{46,47}$. In addition, evidence has indicated an improved survival rate in shrimp primed with killed or attenuated WSSV 24,48 or with WSSV structural subunits.

In conclusion, the antigenicity and immunogenicity of recombinant truncated VP15s and VP15-derived peptides were identified via in vivo animal experiments in Kuruma shrimp ( $M$. japonicus) with a primeand-boost strategy. SR11 (STTAGRISKRR) derived from VP15 ${ }_{(26-57)}$ was successfully identified as an anti-WSSV agent, showing an effective peptide to enhance shrimp persistence against WSSV.

\section{Materials And Methods}

\section{Construction of truncated WSSV-VP15 for expression in $E$. coli.}

In a previous study, the WSSV-VP15 gene (wsv214) fused with a C-terminal Flag-tag (DYKDDDDK) was successfully cloned into pGEX-6P-1, named 'pGEX-VP15'31. For the construction of a series of truncated VP15 proteins (Fig. 1A), inverse PCR was performed with KOD-PLUS-NEO (Toyobo, Japan) using pGEXVP15 as a template. The primers are listed in Table 1. The amplicons were then treated with T4 DNA polymerase (NEB, Tokyo, Japan) according to the manual, self-ligated, and transformed into competent $E$. coli DH5a by the heat-shock method. Colony PCRs were performed using pGEX-FW and pGEX-RV for a comparison between a full-length VP15 and the truncated VP15 series. The pGEX harboring each truncated VP15 gene was prepared from the positive clones, and DNA sequences were verified by Sanger DNA sequencing. For the construction of pGEX-SR11 with a C-terminal Flag-tag, pGEX-VP15 was used as a template in inverse PCR with PrimeSTAR MAX DNA polymerase (Takara, Japan) using PGEX-InvFWISKRR-FLAG and pGEX-InvRV-STTAGR (Table 1). The amplicon was then self-ligated, propagated in $E$. coli DH5a, and verified via DNA sequencing. 
Table 1

Primers used in this study

\begin{tabular}{|ll|}
\hline Name & Sequence (Direction from 5' to 3') $^{\prime}$ \\
\hline pGEX-FW & GAAGTTCTGTTCCAGGGGCCC \\
\hline pGEX-RV & AGGCAGATCGTCAGTCAGTCA \\
\hline pFastBac-FW & TATTCCGGATTATTCATACC \\
\hline pFastBac-RV & ACAAATGTGGTATGGCTGATT \\
\hline pET41-RV & GGTTATGCTAGTTATTGCTC \\
\hline VP15(aa1-25) & \\
\hline pGEX-InvFW-Flag & GACTACAAGGATGACGATGACAAGTAAG \\
\hline VP15tr(aa1-25)-RV & GGAGGAGCGAGCCACCATCTTCAG \\
\hline VP15(aa58-80) & \\
\hline VP15tr(aa58-80)-FW & AAGTCCTCCACCGTGCGT \\
\hline pGEX-InvRV-ATG & CATGGATCCCAGGGGC \\
\hline VP15(aa1-25, 58-80) & \\
\hline VP15tr(aa58-80)-FW & AAGTCCTCCACCGTGCGT \\
\hline VP15tr(aa1-25)-RV & GGAGGAGCGAGCCACCATCTTCAG \\
\hline VP15(aa26-57) & \\
\hline pGEX-InvFW-Flag & GACTACAAGGATGACGATGACAAGTAAG \\
\hline VP15tr(aa26-57)-RV & TTTGCCAGCGCGCTTCTT \\
\hline VP15(SR-11) & \\
\hline pGEX-InvFW-ISKRR-FLAG & ATCTCCAAGCGTCGTGACTACAAGGATGACGATGACAAG \\
\hline pGEX-InvRV-STTAGR & GCGGCCAGCGGTGGTGGACATGGATCCCAGGGGCCCCT \\
\hline MjgC1qR & \\
\hline MjgC1qR-FW-BamHI & ACCAGGATCCATGAGTGCCATCAGTCGTGC \\
\hline MjgC1qR-RV-XhoI-NoStop & TTGTCTCGAGTTTCCTCTTGACAAAGTCCT \\
\hline
\end{tabular}

\section{Expression and purification of recombinant proteins from $E$. coli.}


The verified plasmids were electroporated into E. coli Rosetta gami-B (Novagen, Inc., Tokyo, Japan) before expression of the recombinant protein. Transformed $E$. coli Rosetta gami-B cells were grown overnight at $37^{\circ} \mathrm{C}$ in Lurie-Bertani (LB) broth supplemented with $50 \mu \mathrm{g} / \mathrm{ml}$ ampicillin (LB + Amp). The inoculums were then transferred to baffled flasks containing $250 \mathrm{ml}$ of $\mathrm{LB}+$ Amp medium and incubated at $37^{\circ} \mathrm{C}$ with shaking at $150 \mathrm{rpm}$. When the $\mathrm{OD}_{600}$ reached 0.5 , the culture was cooled on ice for $30 \mathrm{~min}$, protein expression was induced by adding isopropyl $\beta$-D-1-thiogalactopyranoside (IPTG) to a final concentration of $0.5 \mathrm{mM}$ in the culture, and incubation was continued for $18 \mathrm{~h}$ at $16^{\circ} \mathrm{C}$. After $18 \mathrm{~h}$, the cells were collected by centrifugation $\left(6,000 \times \mathrm{g}, 4^{\circ} \mathrm{C}, 15 \mathrm{~min}\right)$, washed twice with phosphate-buffered saline (PBS, $\mathrm{pH} 7.3$ ), and stored at $-80^{\circ} \mathrm{C}$ until use. Protein expression was analyzed via sodium dodecyl sulfate-polyacrylamide gel electrophoresis (SDS-PAGE) and western blotting using anti-DYKDDDDK Ab (1:10000, MBL, Japan).

Before protein purification, the cells were resuspended in PBS containing $1 \times$ proteinase inhibitor (cOmplete Mini, EDTA-free Protease Inhibitor Cocktail, Sigma-Aldrich, Tokyo, Japan) and $10 \mu \mathrm{g} / \mathrm{ml}$ lysozyme. The suspension was sonicated on ice ( $70 \%$ amplitude, $30 \mathrm{sec}$ on/off, 15 cycles), centrifuged $\left(10,000 \times \mathrm{g}, 4^{\circ} \mathrm{C}, 10 \mathrm{~min}\right)$, and filtered through a $0.2 \mu \mathrm{m}$ cellulose acetate membrane (Minisart ${ }^{\circledR} \mathrm{NML}$, Sartorius, Tokyo, Japan). The GST-fused recombinant proteins were purified by GST affinity chromatography (Glutathione Sepharose 4 Fast Flow, GE Healthcare, Tokyo, Japan). Protein concentrations were determined by a Pierce BCA Protein Assay Kit (Thermo Fisher Scientific, Tokyo, Japan) after dialysis against PBS using an Amicon Ultra-15 30K Centrifugal Filter Unit (Merck Japan, Tokyo, Japan).

\section{Cloning of the full-length MjgC1qR gene.}

Total RNA was extracted from adult Kuruma shrimp (10.1 cm of total length and $8.1 \mathrm{~g}$ of body weight) using ISOGEN (Nippon Gene, Tokyo, Japan) according to the manufacturer's protocol. First-strand cDNA was synthesized with $5 \mu \mathrm{g}$ of total RNA using ReverTra Ace (Toyobo, Shiga, Japan) and was kept at $30^{\circ} \mathrm{C}$ until use. The obtained cDNA was used as a template for amplifying the MjgC1qR gene without a stop codon using MjgC1qR-FW-BamHI and MjgC1qR-RV-Xhol-NoStop. The final PCR products were cloned into $\mathrm{pET}-41 \mathrm{a}(+)$ (MERCK Japan) to fuse the gene with a polyhistidine-tagged sequence at the $\mathrm{C}$ terminus (designated pET41-MjgC1qR-His), and positive clones were selected and sequenced. MjgC1qRHis was amplified from pET41-MjgC1qR-His using MjgC1qR-FW-BamHI and pET41-RV and cloned into pFastbac-1 (Thermo Fisher Scientific K. K, Tokyo, Japan), and the product was named pFB-MjgC1qR-His. The sequence was confirmed again via DNA sequencing. All the primers (including their sequences) are listed in Table 1.

\section{Sequence analysis of the MjgC1qR gene.}


The ORF finder (https://www.ncbi.nlm.nih.gov/orffinder/) was used to predict the amino acid sequence. The predicted sequence was analyzed by BLAST (https://blast.ncbi.nlm.nih.gov/Blast.cgi). The protein mass and isoelectric point were theoretically determined by computing the $\mathrm{pl} / \mathrm{Mw}$ tool (https://web.expasy.org/compute_pi/). Mitochondrial targeting sequences and protein domain features were predicted using SMART (Simple Modular Architecture Research Tool, http://smart.emblheidelberg.de/) ${ }^{49}$ and MITOPROT (https://ihg.gsf.de/ihg/mitoprot.html) ${ }^{50}$, respectively. Multiple alignment analysis of MjgC1qR was performed via Clustal Omega software (https://www.ebi.ac.uk/Tools/msa/clustalo/). A phylogenetic tree of gC1qR(s) was generated using the neighbor-joining method in MEGA 7.0.

\section{Generation of a recombinant bacmid encoding MjgC1qR- His and protein expression in silkworm (Bombyx mori) larvae.}

The positive recombinant plasmid pFB-MjgC1qR-His was used to transform E. coli BmDH10Bac for the generation of a recombinant Bombyx mori nucleopolyhedrovirus (BmNPV) bacmid ${ }^{51}$. The bacmid was then transfected into silkworm larvae. Silkworm larvae (Ehime Sansyu, Ehime, Japan) were reared for 5 days with an artificial diet, Silkmate S2 (Nosan, Japan), under a controlled environment $\left(25^{\circ} \mathrm{C}, 65 \pm 5 \%\right.$ relative humidity). Silkworm hemolymph and fat bodies were collected 5 days after bacmid injection. Hemolymph was kept at $-80^{\circ} \mathrm{C}$ as a BmNPV stock for protein expression in silkworms. The fat body was resuspended in lysis buffer $(20 \mathrm{mM}$ Tris- $\mathrm{HCl}, 140 \mathrm{mM} \mathrm{NaCl}$, and $0.1 \%$ Triton X-100, pH 7.6) with proteinase inhibitor added, sonicated, centrifuged, and clarified through a $0.45 \mu \mathrm{m}$ filter. The clarified lysate was subjected to protein expression analysis by western blotting with anti-His antibody (MBL, Nagoya, Japan).

\section{GST pull-down assays.}

The GST pull-down assay was modified based on a method published by Nguyen and Goodrich ${ }^{52}$. In the assay, glutathione Sepharose 4B resins (GE Healthcare Japan, Tokyo, Japan) were first washed and equilibrated four times with PBS. The bait proteins GST (as a negative control), GST-VP15, GST-VP15 ${ }_{(26-}$ 57), or GST-SR11 were immobilized on the resins by adding $500 \mathrm{ml}$ of $E$. coli crude extracts containing the bait protein and incubated at $4^{\circ} \mathrm{C}$ for $4 \mathrm{~h}$ on a rotator shaker. After removing the supernatant, the resins were washed two times with ice-cold TGEM (1.0) $\left[20 \mathrm{mM}\right.$ Tris-HCl (pH 7.9), 20\% glycerol, $5 \mathrm{mM} \mathrm{MgCl}{ }_{2}$, $0.1 \% \mathrm{NP}-40,0.2 \mathrm{mM}$ phenylmethylsulfonyl fluoride (PMSF) and $1.0 \mathrm{M} \mathrm{NaCl}$ ] and two times with ice-cold TGMC (0.1) [20 mM Tris-HCl (pH 7.9), 20\% glycerol, $5 \mathrm{mM} \mathrm{MgCl}_{2}, 5 \mathrm{mM} \mathrm{CaCl}_{2}, 0.1 \%$ NP-40, $0.2 \mathrm{mM} \mathrm{PMSF}$ and $0.1 \mathrm{M} \mathrm{NaCl}$. Then, silkworm extract containing MjgC1qR-His was dialyzed into TGMC(0.1) with $0.1 \%$ Triton X-100. MjgC1qR-His was then added to the immobilized proteins, and the mixture was incubated overnight at $4^{\circ} \mathrm{C}$ on a rotator shaker. After incubation, the resins were washed four times with ice-cold 
TGEM (0.1) [20 mM Tris-HCl (pH 7.9), 20\% glycerol, 5 mM MgCl $2,0.1 \%$ NP-40, $0.2 \mathrm{mM}$ phenylmethylsulfonyl fluoride (PMSF) and $0.1 \mathrm{M} \mathrm{NaCl}$ to remove the unbound target protein. The immobilized proteins on the resins were analyzed by western blotting against GST-tag (anti-GST-tag mAb, MBL, Japan), DYKDDDDK-tag, and His-tag.

\section{Synthesis of the peptides.}

Four VP15-derived peptides (KR11, SR11, SK10, and KK13) (Fig. 3A) were commercially synthesized (GL Biochem Ltd., Shanghai, China). The peptide characteristics were analyzed via high-performance liquid chromatography (HPLC) and electrospray ionization mass spectrometry (ESI-MS). HPLC was employed for purification of each peptide using an Inertsil ODS-SP column (purity $>95 \%$ ). The purity and molecular masses of purified synthetic peptides were analyzed using electrospray ionization coupled with liquid chromatography-mass spectrometry (LC-MS/ESI, Agilent-6125B).

\section{Shrimp and WSSV inoculum.}

Kuruma shrimp (Marsupenaeus japonicus) and the WSSV inoculum were prepared according to a previous method ${ }^{53}$. In brief, shrimp with a mean body weight (MBW) of 3.1 to $6.8 \mathrm{~g}$ were maintained in dechlorinated electrolyzed seawater ( $33.05 \pm 0.13$ parts per trillion) at $24 \pm 1.8^{\circ} \mathrm{C}$ using double-bottomed tanks with sand beds and were fed a commercial diet (shrimp feed, Juveniles P-2, Maruha, Tokyo, Japan) at $3 \%$ of their body weight per day.

Adult M. japonicus (MBW $78 \mathrm{~g}$ ) were intramuscularly (IM)-inoculated with a $10^{-3}$ dilution of a virus prepared from naturally WSSV-infected juvenile shrimp. The hemolymph was withdrawn after 3 days of infection and stored at $-80^{\circ} \mathrm{C}$. Before each experiment, an aliquot of the stored virus was thawed and centrifuged at $1500 \times \mathrm{g}$ at $4^{\circ} \mathrm{C}$ for $10 \mathrm{~min}$. The resultant supernatant was diluted in PBS to $10^{-4.8}$ for the challenge test.

\section{Vaccination and intramuscular (IM) challenge experiment}

Experiment 1: Protective effect of truncated VP15s. Kuruma shrimp (MBW $3.16 \mathrm{~g}, \mathrm{n}=20$ ) were divided into seven groups: five experimental groups and two mock treatment groups. Each group comprised 20 individuals. Shrimp in each experimental group were ( st $^{\text {-injection}) ~ I M-v a c c i n a t e d ~ w i t h ~ V P 15, ~ V P 15 ~}{ }_{(1-25)}$, VP15 $(26-57), \operatorname{VP15}(58-80)$, or VP15 ${ }_{(1-25,58-80)}$ at a dose of $10 \mathrm{mg} / \mathrm{g}$ shrimp. The shrimp were (2 ${ }^{\text {nd }}$-injection $)$ immune-boosted again at 20-day intervals and then IM-challenged with WSSV at a dose of $2.69 \times 10^{4}$ DNA copies/shrimp 10 days after boosting (Fig. 2A). In the mock treatment groups, shrimp were injected with either PBS or GST under the same procedures as in the experimental groups. Shrimp mortality was observed for $20 \mathrm{~d}$ at $24 \mathrm{~h}$ intervals, and the relative percent survival (\%, RPS) was calculated with the formula proposed by Amend ${ }^{54}$ as follows: 


$$
R P S=\left\{1-\left(\frac{\% \text { mortality in immunized group }}{\% \text { mortality in PBS-injected group }}\right)\right\} \times 100
$$

Experiment 2: Screening for an effective peptide derived from VP15. For screening of an effective peptide, juvenile Kuruma shrimp in each group were injected with KR11 ( $n=13), \operatorname{SR} 11(n=11), \operatorname{SK} 10(n=11)$, or KK13 $(n=13)$ at a dose of $10 \mathrm{mg} / \mathrm{g}$ shrimp. Shrimps in each group were then again injected with the peptide to boost their immunity at 20-day intervals. A challenge experiment was performed 10 days after the second injection by injecting the virus at a dose of $2.69 \times 10^{4}$ copies/shrimp, as mentioned above. Shrimps were observed for 15 days, and RPSs were calculated (Fig. 3B). The protective effect of the peptides was compared with that of VP15 $(26-57)(n=11)$.

Experiment 3: Evaluation of SR11, the VP15-derived effective peptide. SR11 was found to be an effective peptide in Experiment 2. SR11 was then verified to have protective effects against a larger shrimp group than VP15 $(26-57)$. Two experimental groups and one PBS control group with 25 individuals/group were set up. Shrimp were injected twice with $10 \mathrm{mg} / \mathrm{g}$ shrimp of the peptide or the recombinant protein at 20day intervals. Ten days after a second injection, shrimp were challenged with WSSV (Fig. 3B). The mortality rate was observed for 20 days, and the RPS was calculated.

\section{Statistical analysis.}

Statistical analysis of the time-mortality relationship was performed with Kaplan-Meier analysis ( $\chi^{2}$ test) at a $5 \%$ confidence level.

\section{Declarations}

\section{Author Contributions}

J.B.: Investigation, methodology, and writing - original draft preparation. J.X.: Formal analysis, review \& editing. T.N.: Methodology. J.S.: Methodology, investigation. T.K.: Review \& editing. E.Y.P.:

Conceptualization, funding acquisition, writing - revision \& editing.

\section{Funding information}

This work was supported by the Yanmar Environmental Sustainability Support Association (KI0201004).

\section{Compliance with Ethical Standards}

None 


\section{Conflict of interest}

The authors declare that they have no conflicts of interest.

\section{References}

1. Zwart, M. P., Dieu, B. T. M., Hemerik, L. \& Vlak, J. M. Evolutionary Trajectory of White Spot Syndrome Virus (WSSV) Genome Shrinkage during Spread in Asia. PLOS ONE 5, e13400, doi:https://doi.org/10.1371/journal.pone.0013400 (2010).

2. Wang, Y. G., Hassan, M. D., Shariff, M., Zamri, S. M. \& Chen, X. Histopathology and cytopathology of white spot syndrome virus (WSSV) in cultured Penaeus monodon from peninsular Malaysia with emphasis on pathogenesis and the mechanism of white spot formation. Dis. Aquat. Org. 39, 1-11 https://doi.org/https://doi:10.3354/dao039001 (1999).

3. Chou, H. Y., Huang, C. Y., Wang, C. H., Chiang, H. C. \& Lo, C. F. Pathogenicity of a baculovirus infection causing white spot syndrome in cultured penaeid shrimp in Taiwan. Dis. Aquat. Org. 23, 165-173 https://doi.org/10.3354/dao023165 (1995).

4. Escobedo-Bonilla, C. M., Vega-Peña, S. \& Mejía-Ruiz, C. H. Efficacy of double-stranded RNA against white spot syndrome virus (WSSV) non-structural (orf89, wsv191) and structural (vp28, vp26) genes in the Pacific white shrimp Litopenaeus vannamei. Journal of King Saud University - Science. 27, 182-188 https://doi.org/10.1016/j.jksus.2014.11.004 (2015).

5. Lo, C. F. et al. White spot syndrome baculovirus (WSBV) detected in cultured and captured shrimp, crabs and other arthropods. Dis. Aquat. Org. 27, 215-225 https://doi.org/10.3354/dao027215 (1996).

6. Pradeep, B. et al. Host Range, Pathogenesis and Diagnosis of White spot syndrome virus. Indian J. Virol. 23, 161-174 https://doi.org/10.1007/s13337-012-0079-y (2012).

7. Sánchez-Paz, A. White spot syndrome virus: an overview on an emergent concern. Vet. Res. 41, 43 https://doi.org/10.1051/vetres/2010015 (2010).

8. Durand, S., Lightner, D. V., Redman, R. M. \& Bonami, J. R. Ultrastructure and morphogenesis of white spot syndrome baculovirus (WSSV). Dis. Aquat. Org. 29, 205-211 (1997).

9. Nadala, E. C. J. \& Tapay, L. M. Characterization of a non-occluded baculovirus-like agent pathogenic to penaeid shrimp. Dis. Aquat. Org. 33, 221-229 https://doi.org/doi:10.3354/dao033221 (1998).

10. Parrilla-Taylor, D. P. et al. Molecular variability and genetic structure of white spot syndrome virus strains from northwest Mexico based on the analysis of genomes. FEMS Microbiol. Lett. 365, fny216 https://doi.org/10.1093/femsle/fny216 (2018).

11. Oakey, H. J. \& Smith, C. S. Complete genome sequence of a white spot syndrome virus associated with a disease incursion in Australia. Aquaculture. 484, 152-159 https://doi.org/10.1016/j.aquaculture.2017.11.009 (2018). 
12. van Hulten, M. C. W. et al. The White Spot Syndrome Virus DNA Genome Sequence. Virology. 286, 722 https://doi.org/10.1006/VIRO.2001.1002 (2001).

13. et al. Construction and Application of a Protein Interaction Map for White Spot Syndrome Virus (WSSV). Molecular \& Cellular Proteomics 13, 269-282, doi:10.1074/mcp.M113.029199 (2014).

14. Xie, X., Xu, L. \& Yang, F. Proteomic Analysis of the Major Envelope and Nucleocapsid Proteins of White Spot Syndrome Virus. J. Virol. 80, 10615-10623 https://doi.org/10.1128/JVI.01452-06 (2006).

15. Tsai, J. M. et al. Identification of the Nucleocapsid, Tegument, and Envelope Proteins of the Shrimp White Spot Syndrome Virus Virion. J. Virol. 80, 3021-3029 https://doi.org/10.1128/JVI.80.6.30213029.2006 (2006).

16. Huang, P. Y., Leu, J. H. \& Chen, L. L. A newly identified protein complex that mediates white spot syndrome virus infection via chitin-binding protein. J. Gen. Virol. 95, 1799-1808 https://doi.org/10.1099/vir.0.064782-0 (2014).

17. Chang, Y. S. et al. A 3D Model of the Membrane Protein Complex Formed by the White Spot Syndrome Virus Structural Proteins. PLOS ONE. 5, e10718 (2010).

18. Zhou, Q., Xu, L., Li, H., Qi, Y. P. \& Yang, F. Four Major Envelope Proteins of White Spot Syndrome Virus Bind To Form a Complex. J. Virol. 83, 4709-4712 https://doi.org/10.1128/jvi.02360-08 (2009).

19. Chang, Y. H., Kumar, R., Ng, T. H. \& Wang, H. C. What vaccination studies tell us about immunological memory within the innate immune system of cultured shrimp and crayfish. Dev. Comp. Immunol. 80, 53-66 https://doi.org/10.1016/j.dci.2017.03.003 (2018).

20. Dey, B. K., Dugassa, G. H., Hinzano, S. M. \& Bossier, P. Causative agent, diagnosis and management of white spot disease in shrimp: A review. Reviews in Aquaculture. 12, 822-865 https://doi.org/10.1111/raq.12352 (2020).

21. Witteveldt, J., Vlak, J. M. \& van Hulten, M. C. W. Protection of Penaeus monodon against white spot syndrome virus using a WSSV subunit vaccine. Fish Shellfish Immunol. 16, 571-579 https://doi.org/10.1016/j.fsi.2003.09.006 (2004).

22. Thomas, A. et al. Immunogenicity and protective efficacy of a major White Spot Syndrome Virus (WSSV) envelope protein VP24 expressed in Escherichia coli against WSSV. J. Invertebr. Pathol. 123, 17-24 https://doi.org/10.1016/j.jip.2014.08.004 (2014).

23. Satoh, J., Nishizawa, T. \& Yoshimizu, M. Protection against white spot syndrome virus (WSSV) infection in kuruma shrimp orally vaccinated with WSSV rVP26 and rVP28. Dis. Aquat. Org. 82, 8996 https://doi.org/10.3354/dao01978 (2008).

24. Vaseeharan, B., Anand, P., Murugan, T. \& Chen, J. C. Shrimp vaccination trials with the VP292 protein of white spot syndrome virus. Lett. Appl. Microbiol. 43, 137-142 https://doi.org/10.1111/j.1472765X.2006.01941.x (2006).

25. Ye, T., Zong, R. \& Zhang, X. The role of white spot syndrome virus (WSSV) VP466 protein in shrimp antiviral phagocytosis. Fish Shellfish Immunol. 33, 350-358 https://doi.org/10.1016/j.fsi.2012.05.017 (2012). 
26. Boonyakida, J. et al. Antigenic properties of VP15 from white spot syndrome virus in kuruma shrimp Marsupenaeus japonicus. Fish Shellfish Immunol. 101, 152-158 https://doi.org/10.1016/j.fsi.2020.03.061 (2020).

27. van Hulten, M., Reijns, M., Vermeesch, M. G., Zandbergen, A. \& Vlak, J. Identification of VP19 and VP15 of white spot syndrome virus (WSSV) and glycosylation status of the WSSV major structural proteins. The Journal of general virology. 83, 257-265 https://doi.org/10.1099/0022-1317-83-1-257 (2002).

28. Liu, Y., Wu, J., Chen, H., Hew, C. L. \& Yan, J. DNA condensates organized by the capsid protein VP15 in White Spot Syndrome Virus. Virology. 408, 197-203 https://doi.org/10.1016/j.virol.2010.09.008 (2010).

29. Witteveldt, J. et al. Nucleocapsid protein VP15 is the basic DNA binding protein of white spot syndrome virus of shrimp. Arch. Virol. 150, 1121-1133 https://doi.org/10.1007/s00705-004-0483-8 (2005).

30. Rout, N., Kumar, S., Jaganmohan, S. \& Murugan, V. DNA vaccines encoding viral envelope proteins confer protective immunity against WSSV in black tiger shrimp. Vaccine. 25, 2778-2786 https://doi.org/10.1016/j.vaccine.2006.12.056 (2007).

31. Shen, S. et al. Characterization of a gC1qR homolog from sea cucumber Apostichopus japonicus. Fish Shellfish Immunol. 93, 216-222 https://doi.org/10.1016/j.fsi.2019.07.058 (2019).

32. Sun, B. et al. Characterization and expression analysis of a gC1qR gene from Macrobrachium nipponense under ammonia-N stress. Aquaculture. 513, 734426 https://doi.org/10.1016/j.aquaculture.2019.734426 (2019).

33. Jiang, S. et al. A C1q domain containing protein from Crassostrea gigas serves as pattern recognition receptor and opsonin with high binding affinity to LPS. Fish Shellfish Immunol. 45, 583591 https://doi.org/10.1016/j.fsi.2015.05.021 (2015).

34. Braun, L., Ghebrehiwet, B. \& Cossart, P. gC1q-R/p32, a C1q-binding protein, is a receptor for the InIB invasion protein of Listeria monocytogenes. The EMBO Journal. 19, 145-1466 https://doi.org/10.1093/emboj/19.7.1458 (2000).

35. Ye, T. et al. Characterization of a gC1qR from the giant freshwater prawn, Macrobrachium rosenbergii. Fish Shellfish Immunol. 43, 200-208 https://doi.org/10.1016/j.fsi.2014.12.030 (2015).

36. Li, X. C. et al. A novel pathogen-binding gC1qR homolog, $\mathrm{FcgC1qR}$, in the Chinese white shrimp, Fenneropenaeus chinensis. Dev. Comp. Immunol. 36, 400-407 https://doi.org/10.1016/j.dci.2011.08.005 (2012).

37. Yang, L. et al. Characterization of complement 1q binding protein of tiger shrimp, Penaeus monodon, and its C1q binding activity. Fish Shellfish Immunol. 34, 82-90 https://doi.org/10.1016/j.fsi.2012.10.002 (2013).

38. Ning, J., Liu, Y., Gao, F., Liu, H. \& Cui, Z. Characterization and functional analysis of a novel gC1qR in the swimming crab Portunus trituberculatus. Fish Shellfish Immunol. 84, 970-978 https://doi.org/10.1016/j.fsi.2018.11.005 (2019). 
39. Dedio, J., Jahnen-Dechent, W., Bachmann, M. \& Müller-Esterl, W. The Multiligand-Binding Protein gC1qR, Putative C1q Receptor, Is a Mitochondrial Protein. The Journal of Immunology. 160, 35343542 (1998).

40. Norouzitallab, P., Baruah, K., Biswas, P., Vanrompay, D. \& Bossier, P. Probing the phenomenon of trained immunity in invertebrates during a transgenerational study, using brine shrimp Artemia as a model system. Sci. Rep. 6, 21166 https://doi.org/10.1038/srep21166 (2016).

41. Lin, Y. C. et al. Vaccination Enhances Early Immune Responses in White Shrimp Litopenaeus vannamei after Secondary Exposure to Vibrio alginolyticus. PLOS ONE. 8, e69722 https://doi.org/10.1371/journal.pone.0069722 (2013).

42. Powell, A. et al. Enhanced immune defences in Pacific white shrimp (Litopenaeus vannamei) postexposure to a vibrio vaccine. J. Invertebr. Pathol. 107, 95-99 https://doi.org/10.1016/j.jip.2011.02.006 (2011).

43. Namikoshi, A. et al. Vaccination trials with Penaeus japonicus to induce resistance to white spot syndrome virus. Aquaculture. 229, 25-35 https://doi.org/10.1016/S0044-8486(03)00363-6 (2004).

44. Letunic, I., Khedkar, S. \& Bork, P. SMART: recent updates, new developments and status in 2020. Nucleic Acids Res., gkaa937, doi:10.1093/nar/gkaa937 (2020).

45. Claros, M. G. \& Vincens, P. Computational method to predict mitochondrially imported proteins and their targeting sequences. Eur. J. Biochem. 241, 779-786 (1996).

46. Kato, T., Arai, S., Ichikawa, H. \& Park, E. Y. Versatility of chitosan/BmNPV bacmid DNA nanocomplex as transfection reagent of recombinant protein expression in silkworm larvae. Biotechnol. Lett. 38, 1449-1457 https://doi.org/10.1007/s10529-016-2144-x (2016).

47. Nguyen, T. N. \& Goodrich, J. A. Protein-protein interaction assays: eliminating false positive interactions. Nat. Methods. 3, 135-139 https://doi.org/10.1038/nmeth0206-135 (2006).

48. Wu, J. L., Nishioka, T., Mori, K., Nishizawa, T. \& Muroga, K. A time-course study on the resistance of Penaeus japonicus induced by artificial infection with white spot syndrome virus. Fish Shellfish Immunol. 13, 391-403 https://doi.org/10.1006/fsim.2002.0414 (2002).

49. Amend, D. F. Potency testing of fish vaccines.Fish biologics: serodiagnostics and vaccines,447454(1981).

50. 50. Claros, M. G. \& Vincens, P. Computational method to predict mitochondrially imported proteins and their targeting sequences. Eur. J. Biochem. 241, 779-786 (1996).

51. 51. Kato, T., Arai, S., Ichikawa, H. \& Park, E. Y. Versatility of chitosan/BmNPV bacmid DNA nanocomplex as transfection reagent of recombinant protein expression in silkworm larvae. Biotechnol. Lett. 38, 1449-1457, doi:10.1007/s10529-016-2144-x (2016).

52. 52. Nguyen, T. N. \& Goodrich, J. A. Protein-protein interaction assays: eliminating false positive interactions. Nat. Methods 3, 135-139, doi:10.1038/nmeth0206-135 (2006).

53. 53. Wu, J. L., Nishioka, T., Mori, K., Nishizawa, T. \& Muroga, K. A time-course study on the resistance of Penaeus japonicus induced by artificial infection with white spot syndrome virus. Fish Shellfish Immunol. 13, 391-403, doi:https://doi.org/10.1006/fsim.2002.0414 (2002). 
54. 54. Amend, D. F. Potency testing of fish vaccines. Fish biologics: serodiagnostics and vaccines, 447454 (1981).

\section{Figures}

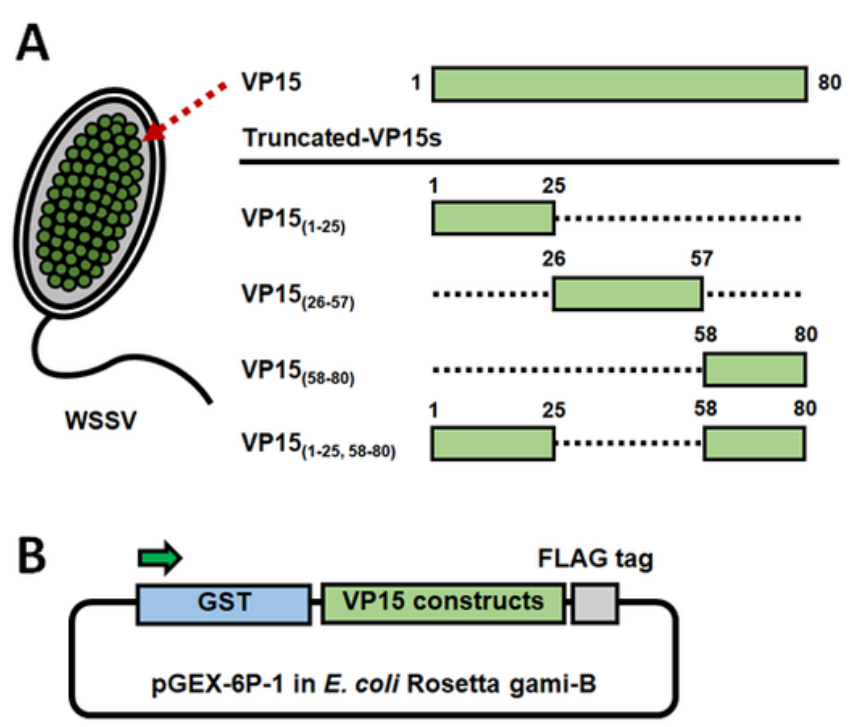

Fig. 1, Boonyakida et al.

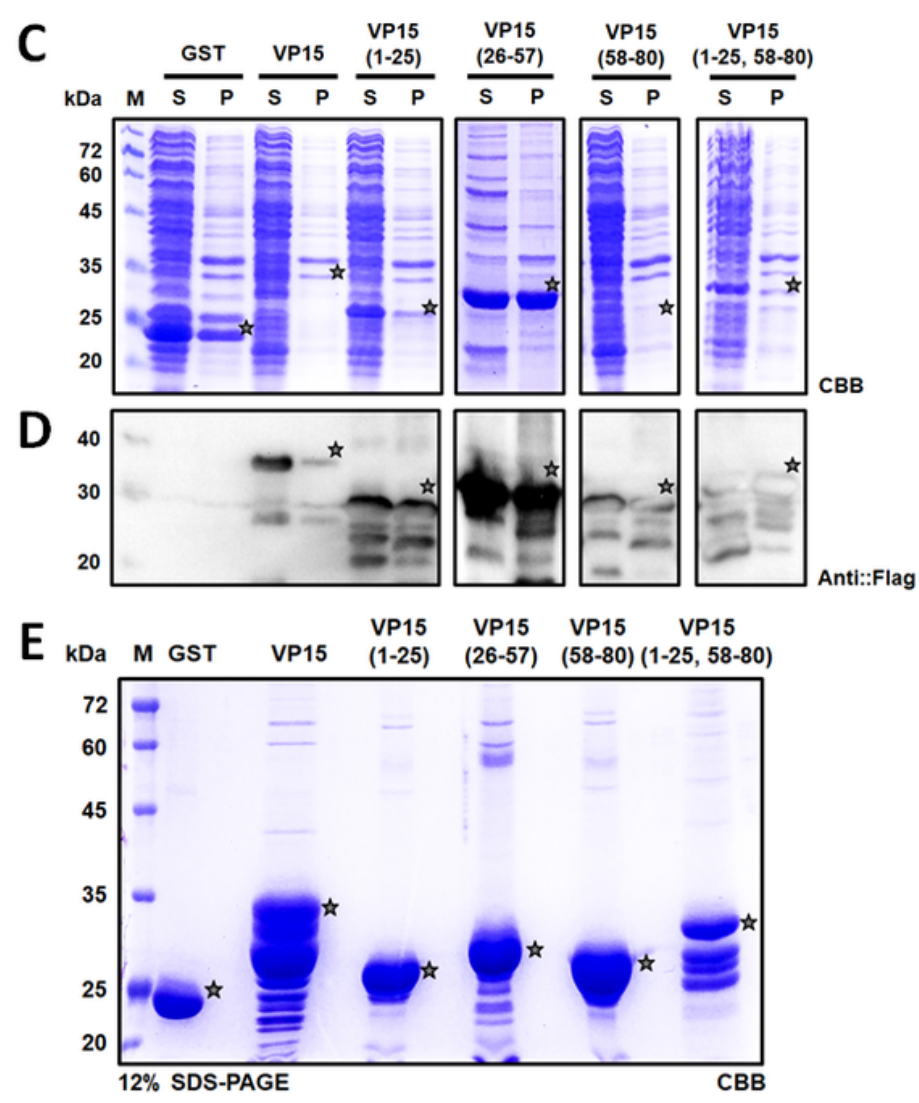

\section{Figure 1}

Expression of the truncated WSSV-VP15 series using the E. coli expression system. (A). Schematic diagram representing a major nucleocapsid protein of WSSV-VP15. Four truncated VP15 constructs were generated as illustrated and were named VP15(1-25), VP15(26-57), VP15(58-80), and VP15(1-25,5880). The numbers represent the amino acid position. (B) Construction of plasmids harboring the VP15 truncated series for expression using the E. coli system and expression verification via SDS-PAGE. GST: glutathione-S-transferase as a fusion tag and for affinity purification; Flag: DYKDDDDK epitope tag for western blot analysis. (C) Coomassie brilliant blue-stained SDS-PAGE gel of E. coli expressing VP15 truncated constructs and (D) western blot analysis of the expressed recombinant proteins. Anti-Flag antibody was applied for the detection of the target proteins. M: marker; S: supernatant; and P: precipitate. Original gel images of GST, VP15, VP15(1-25), VP15(58-80), and VP15(1-25,58-80) in C and D are shown in Supplementary information Fig. S1; that of VP15(26-57) in C and D, Supplementary information Fig. S2. (E) SDS-PAGE analysis of purified VP15 and truncated VP15 series. Each recombinant protein was purified via GST affinity chromatography. The theoretical sizes of VP15, VP15(1-25), VP15(26-57), VP15(58-80), and VP15(1-25,58-80) were 37.0, 30.8, 31.6, 30.5, and 33.4 
$\mathrm{kDa}$, respectively. VP15(1-25), VP15(26-57), and VP15(58-80) can be obtained with a single main band. However, a purified product of VP15 and VP15(1-25,58-80) has several productive products below the main product. GST was loaded as a control. M indicates a protein marker.
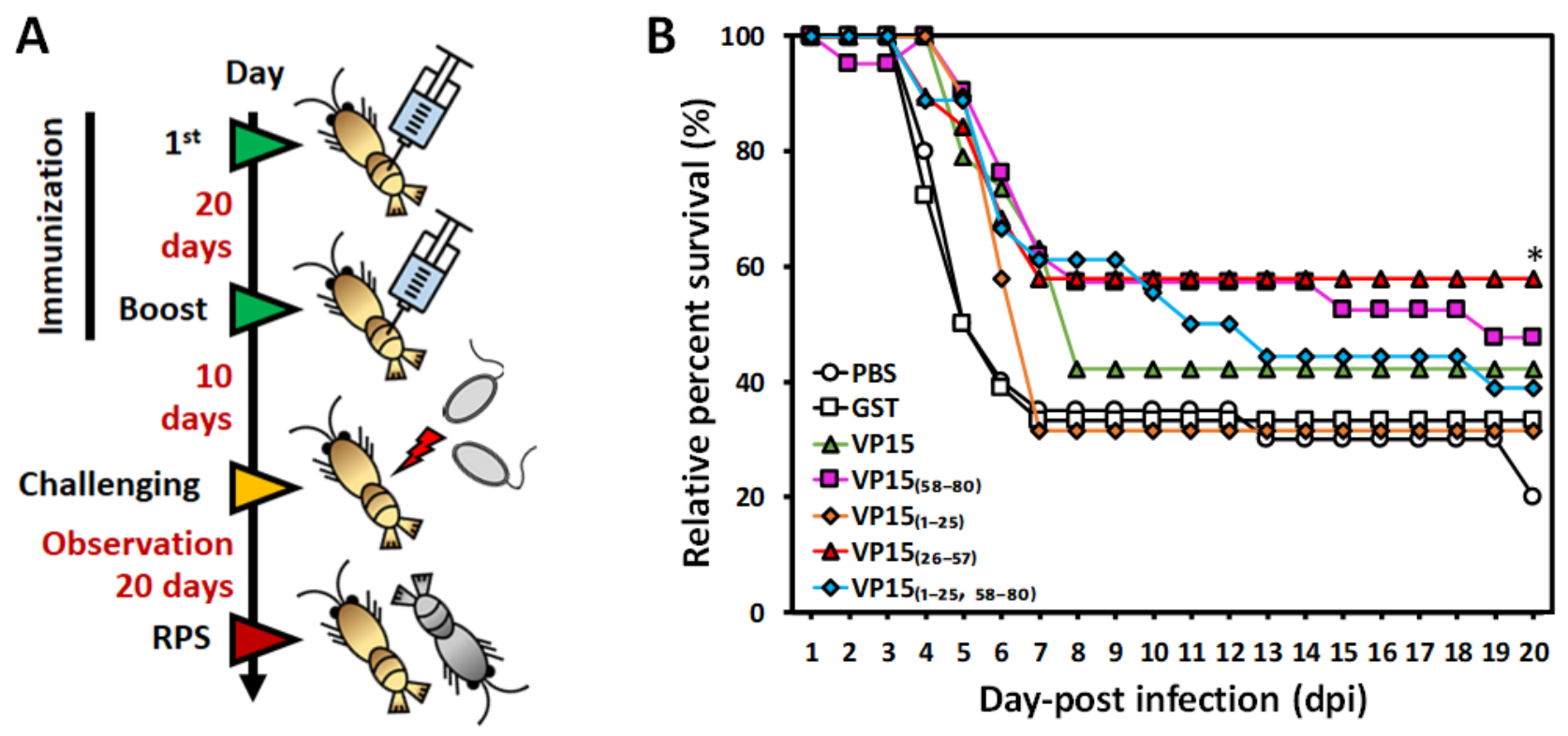

Fig. 2, Boonyakida et al.

Figure 2

Evaluation of the E. coli-derived WSSV-VP15 and truncated VP15s for protective effects against WSSV. (A) Time schedule of shrimp immunization, WSSV challenge, and observation. The prime-and-boost immunization strategies for seven different groups (PBS, GST, VP15, VP15(1-25), VP15(26-57), VP15(58-80), and VP15(1-25, 58-80)) are shown. In brief, shrimp were immune primed and boosted at day 0 and day 20 and challenged with WSSV via intramuscular injection 10 days afterward. (B) Time course of the RPS of Kuruma shrimp after WSSV challenge. The mortality of shrimp was observed for 20 days at $24 \mathrm{~h}$ intervals. The line marked with an asterisk is significantly higher than that of the control groups. 

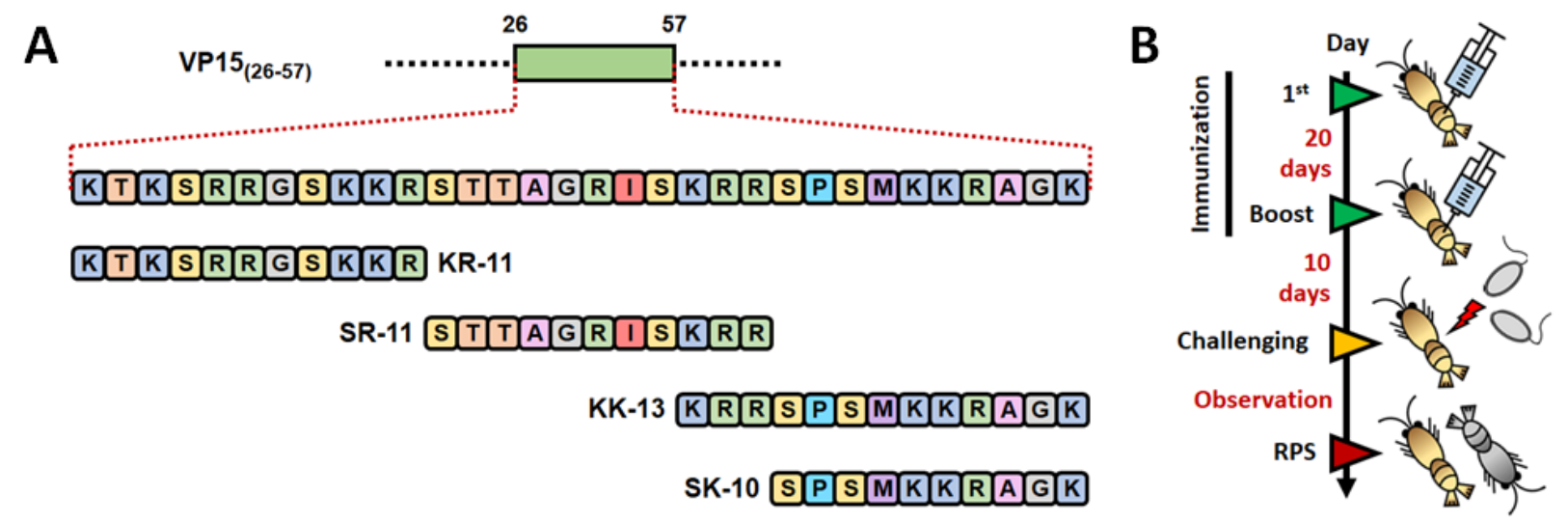
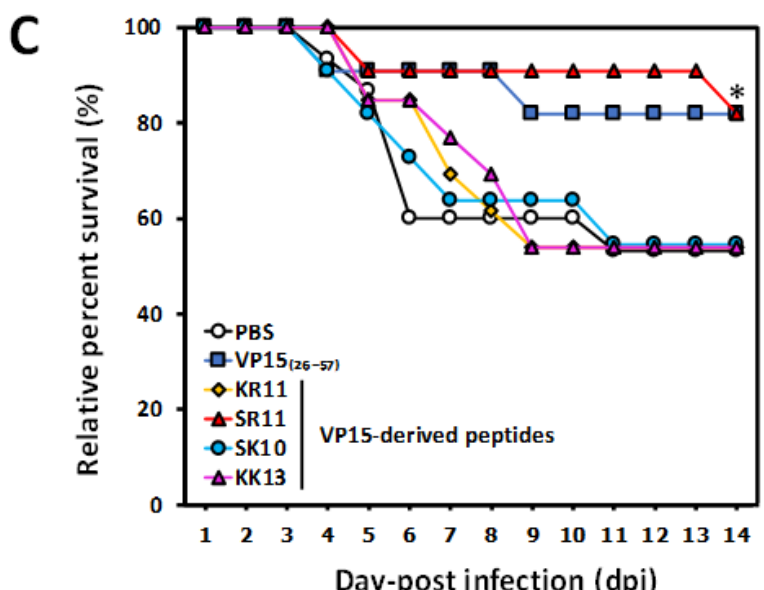

Fig. 3, Boonyakida et al.
KUKS RRISAKR KR-11

SR-11 STTAGRTSRRR

KK-13 KRTRSPS M K K R A G

SK-10 STIS K K RAGK

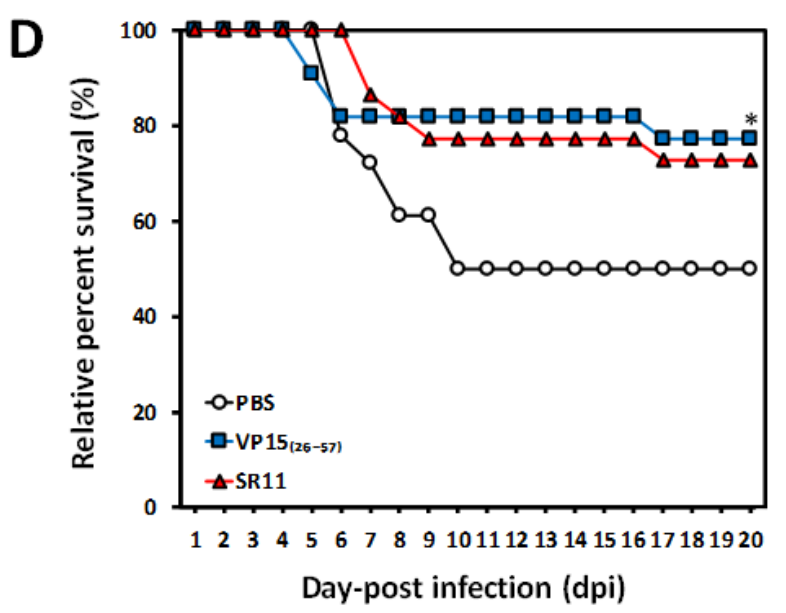

\section{Figure 3}

Peptide design and evaluation of VP15-derived peptides in shrimp against WSSV. (A) De novo design of peptides using the VP15(26-57) amino acid sequence as a template. Four peptides, named KR11 (KTKSRRGSKKR), SR11 (STTAGRISKRR), SK10 (SPSMKKRAGK), and KK13 (KRRSPSMKKRAGK) were designed and chemically synthesized. (B) Time schedule of shrimp experiments using VP15-derived peptides as a protective agent. (C) Screening for the effective peptide by shrimp WSSV challenge experiment (KR11 ( $=13)$, SR11 ( $=11)$, SK10 $(n=11)$, or KK13 $(n=13))$. Shrimp mortality was observed for 14 days, and the RPS of each group was calculated. (D) Evaluation of SR11, an effective peptide, for enhancing shrimp survivability against WSSV. The experiment was conducted with twice the number of individuals $(\mathrm{n}=25)$. For both experiments, VP15 (26-57) was used as a positive control, while PBS served as a negative control. 


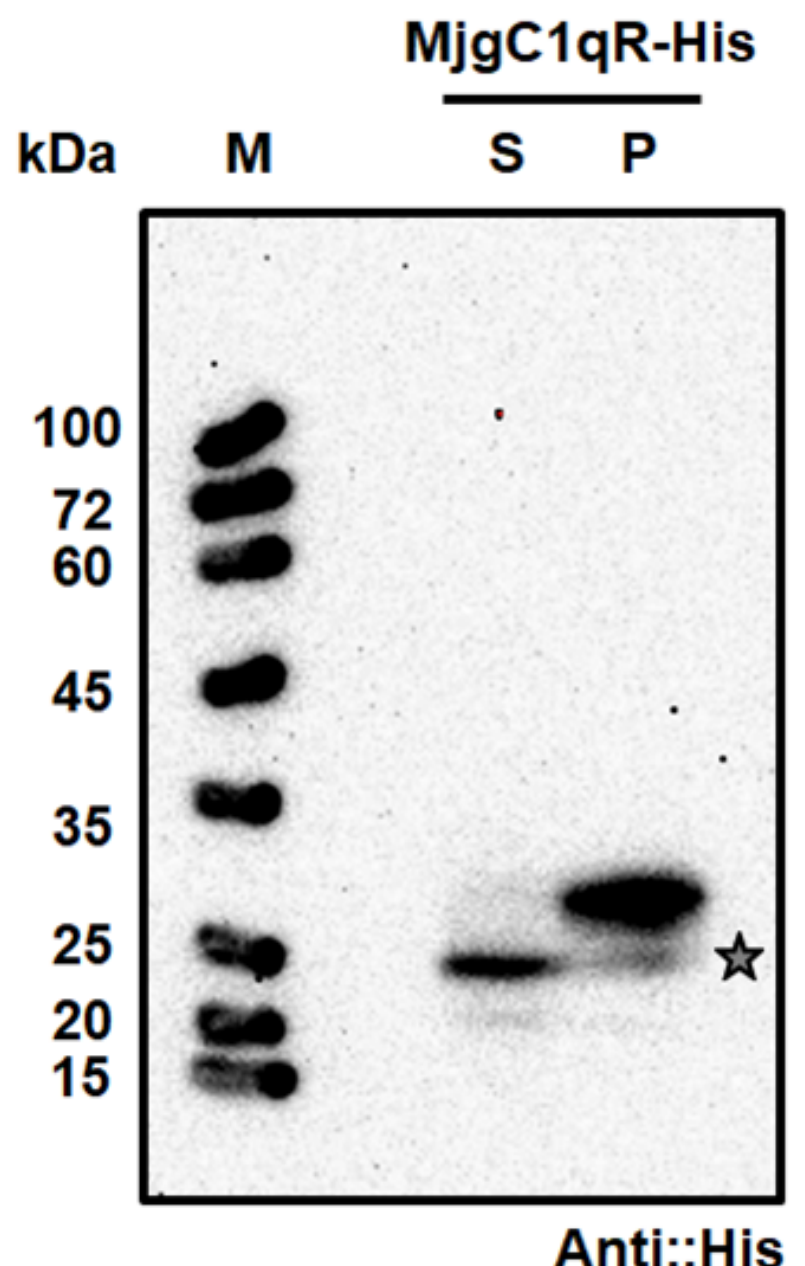

Fig. 4, Boonyakida et al.

Figure 4

Western blot analysis of MjgC1qR expressed in silkworm larvae. Western blot analysis of silkworms was performed with an anti-His antibody. Silkworms were transfected with recombinant bacmid harboring the MjgC1qR-His construct, and fat bodies were collected after 5 days of transfection. M: marker; S:

supernatant; and P: precipitate. 
A

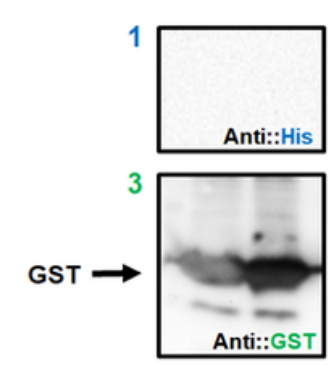

,
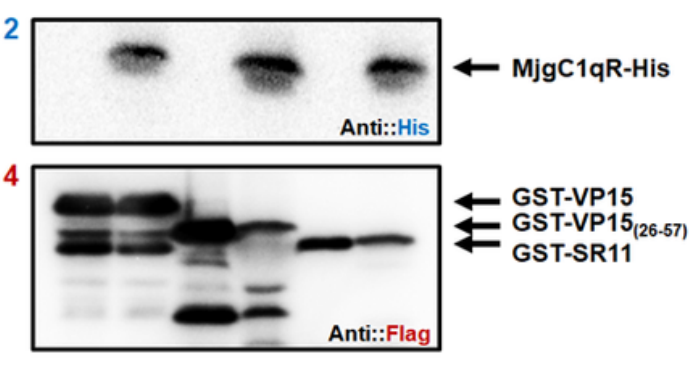

GST

GST-VP15

GST-VP15 (26-57)

GST-SR11

MjgC1qR-His

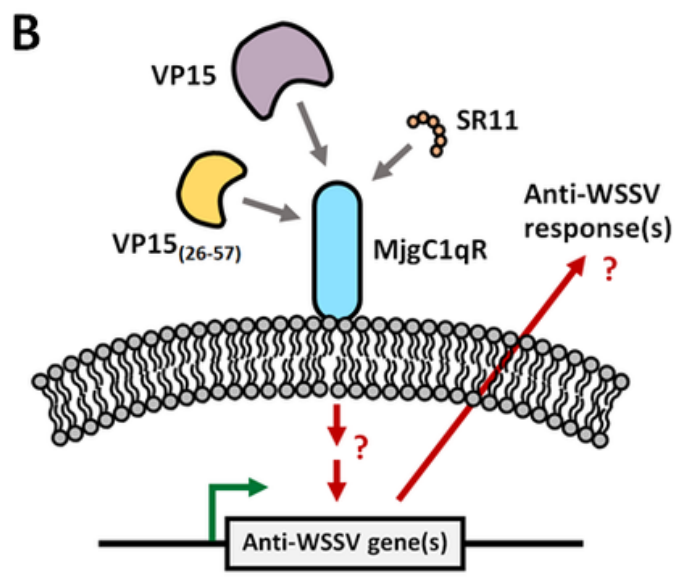

Fig. 5, Boonyakida et al.

Figure 5

GST pull-down assay between MjgC1qR and GST-VP15, GST-VP15(26-57), GST-SR11, and a proposed antiviral mechanism. (A) The interaction of MjgC1qR-His with GST-VP15, GST-VP15(26-57), and GSTSR11 was observed via GST pull-down assay and confirmed by western blot analysis with (1 and 2) antiHis antibody, (3) anti-GST antibody, and (4) anti-Flag antibody. The symbol " + " indicates the proteins used for the assay. The original full-length blots of $A$ are shown in Supplementary information Fig. S7. (B) In shrimp, VP15, VP15(26-57), and SR11 interacted with the host gC1qR, hence inducing an unknown cellular signaling cassette that could activate the transcription of antimicrobial peptides.

\section{Supplementary Files}

This is a list of supplementary files associated with this preprint. Click to download.

- SIJB0109.pdf 